\title{
Microstructural Characterization of Eutectoid Steel Strips
}

\author{
Janos Dobranszky ${ }^{1}$ \\ ${ }^{1}$ Research Group for Metals Technology of the Hungarian Academy of Sciences \\ Goldmann ter 3, 1111 Budapest, Hungary \\ E-mail: dobi@eik.bme.hu
}

Keywords: eutectoid steels, microstructural analysis, thermoelectric power, retained austenite.

\begin{abstract}
Investigations of microstructural differences of tempered eutectoid steel strips are presented. The constituent phases - fine mixture of ferrite and cementite and a small amount of retained austenite - considerably affect the mechanical properties, especially the resistance to high cycle fatigue. The amount of retained austenite was determined by XRD and EBSD analysis. Thermoelectric power (TEP) measurements were performed for 270 different batches of C75S type eutectoid steel strips. TEP measurement shows characteristically the fine microstructural differences. The TEP of the investigated samples varied between 5650 and $7030 \mathrm{nV} /{ }^{\circ} \mathrm{C}$. The amount of retained austenite can be significantly higher at the surface $(20 \%)$ than at the internal part $(0-5 \%)$. The sensitivity of XRD analysis was reduced because of the presence of coarse cementite particles. Using $\mathrm{Cu}$ anode, the measurements were more successful than in case of using Co anode. The EBSD analysis showed that also samples immeasurable with XRD contain retained austenite, but its detectability with XRD analysis declines with the coarsening of cementite.
\end{abstract}

\section{Introduction}

The unalloyed eutectoid steel strips are widely used tool materials. They are base materials of bandsaw blades. A very important requirement is to have for a long time the stress structure, which was generated at the producing of bandsaw applying precise pressure plastic deformation on the surface: this production technology provides the long-term cutting precision.

According to the experiences of the greatest Hungarian bandsaw blade producer ( $A-L A P L t d$.), there are significant differences between the bandsaw blades produced using the same steel type of the same or different producer of the tempered steel strips. Despite of the fact that the conventional mechanical properties - yield strength, hardness and plastic strain for example - are also the same, the stress structure stability and the fatigue resistance can be very different - even in case of steel strips which originate from the same producer. This paper represents a stage of the research going on for years, which deals with the fine microstructural differences of the steel strips. Among the microstructural properties of steels with the same composition the most important ones are the particle size of the main phases, the ferrite and the cementite. Besides the presence, amount and distribution of retained austenite phase can have an important effect on the characteristics.

The retained austenite in the tempered steel strips can have a pronounced effect on the cutting characteristics and lifetime of bandsaw blades. This metastable phase can improve product strength because of its hardening capability [1]. Austenite forms in eutectoid steels at the austenitization period of continuous tempering. During quenching austenite can be transformed into martensite, therefore, the gamma to martensite phase transformation is generally not perfect; consequently, the retained austenite that can also remain after the tempering of martensite [2] can further transform during the service of the bandsaw into deformation induced martensite.

Retained austenite content in the tempered steels can be measured by Mössbauer-spectroscopy and X-ray diffraction (XRD) analysis [3], which powerful method is commonly non-destructive and can precisely measure the amount of retained austenite as low as one percent. Unfortunately, many variables, such as grain size, preferred orientation, high amount of cementite, etc., can significantly affect the results and so those influence the precision of measurement unfavourably. 
In the first step of the investigation a lot of C75S type eutectoid steel strips (EN 10132-4) were examined by thermoelectric power measurements. The thermoelectric power (TEP) measurement is based on the first known (since 1826) thermoelectric phenomenon, which is the Seebeck-effect. The principle of Seebeck-effect said that if a temperature gradient is forming in a conductor material, at the same time an electric potential difference develops, that depends on the temperatures difference. The thermoelectric power - otherwise known as Seebeck-coefficient - can be described as the ratio of the total voltage generated by a given temperature difference.

The TEP measurement technique can sensitively characterize the processes connected to the diffusion of interstitial alloying elements, such as carbon or nitrogen [4-7], the changing of dislocation structure and the tempering processes or dimension changes of martensitic bearing steels $[2,8]$. The thermoelectric measurements can be coupled simply with the micromagnetic measurements. The TEP measurement can be used successfully for the characterization of many segregation and precipitation governed phase transformations in multi-phase steels and alloys, e.g. austenitic steels $[9,10]$, Mo-alloyed creep resistant steels $[11,12]$ and duplex stainless steels [13]. The thermoelectric power measurements play more and more important role in the investigation of retained austenite stability in transformation induced plasticity (TRIP) steels [14,15].

\section{Thermoelectric power measurements}

The TEP measurements were performed on samples taken from 270 different coils made of C75S type unalloyed tool steel. The device used for the TEP measurements was developed at INSA de Lyon GEMPPM and produced by TechLab. The ambient temperature was $+20^{\circ} \mathrm{C}$, the temperature of the copper measuring blocks were $+15{ }^{\circ} \mathrm{C}$ and $+25^{\circ} \mathrm{C}$, and their distance was $70 \mathrm{~mm}$.

All the 270 tempered steel strips - with thickness 0,4-1 $\mathrm{mm}$ and width $22-120 \mathrm{~mm}$ - were produced by the same steel producer. The examined steel strips by dimensions belonged to 24 groups. For measuring TEP of strips, 2 samples were taken from all the strips with the same width $(5 \mathrm{~mm})$ and length $(90 \mathrm{~mm})$ : one from both ends of the coils. Altogether 8 TEP data were obtained by measurement of the two samples for each steel strip, and the average values were composed of the data originating from the same size samples; Fig. 1 shows the averaged data.

The division of the TEP values is shown by two parameters, 3D diagram in Fig. 1a: the value of TEP shows varying between +715 and $-670 \mathrm{nV} /{ }^{\circ} \mathrm{C}$ compared to the main average value $(6300$ $\mathrm{nV} /{ }^{\circ} \mathrm{C}$ ). The mathematical-statistical evaluation of the whole data block by the Box and Whiskersmethod explored several inherence between the measurement results, but these are to present in an other work. Fig. $1 b$ makes the division of the results easy to survey by a „greyscale map" diagram: the groups made by the strip dimensions are clearly separated in the width versus length diagram and the TEP values are defined on the grey scale.
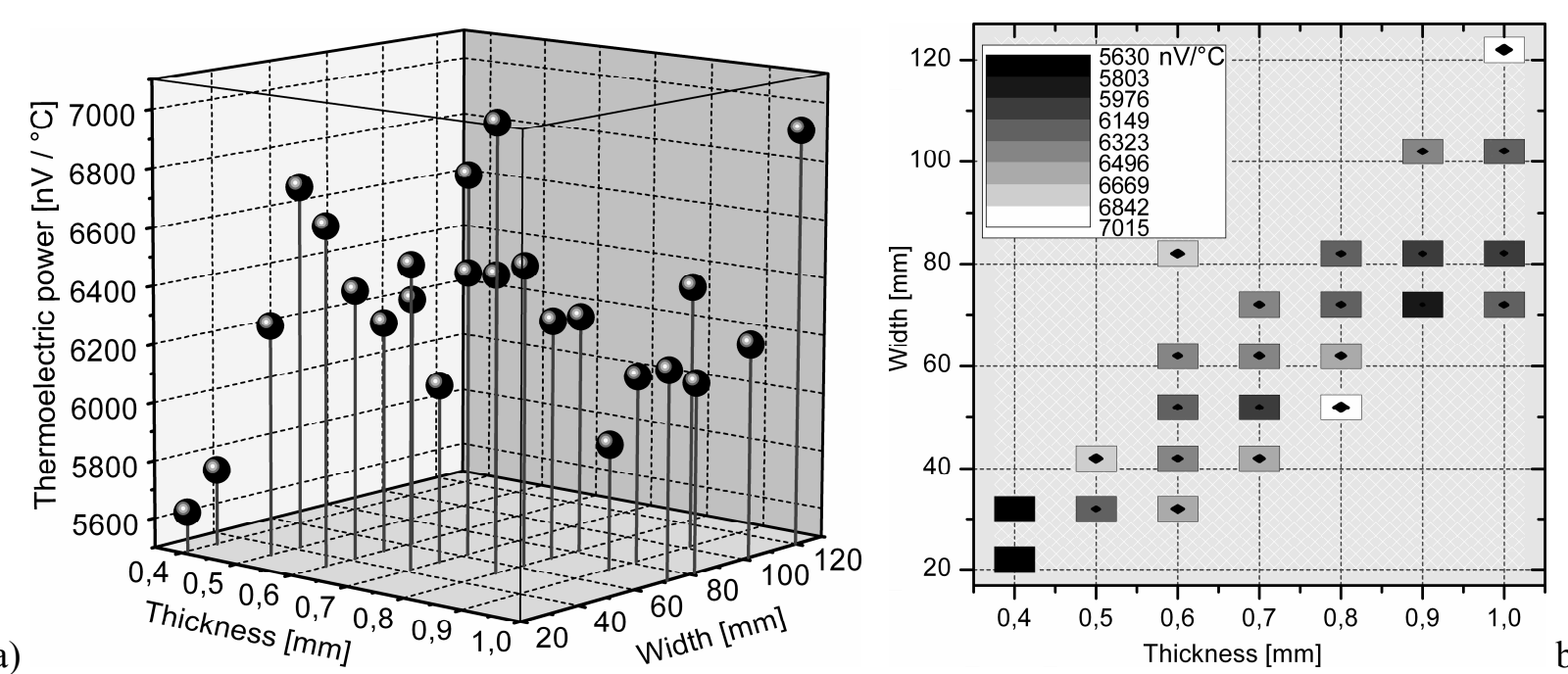

Figure 1. Averaged TEP of C75S steel strips in 3D scatter diagram (a) and in greyscale map (b). 
The measured data separated by the thickness and width of strip also are shown in Fig. 2. It can be observed in case of two strip geometry - the $0,8 \times 52 \mathrm{~mm}$ one and the $1,0 \times 120 \mathrm{~mm}$ one - which have extremely high Seebeck-coefficient. At the same time the minimum TEP values are shown at two strips of the thickness $0,4 \mathrm{~mm}$. At the other twenty steel strip groups given by the dimensions TEP values are moving in a much narrower zone and plotted against thickness; they show a moderate decline.
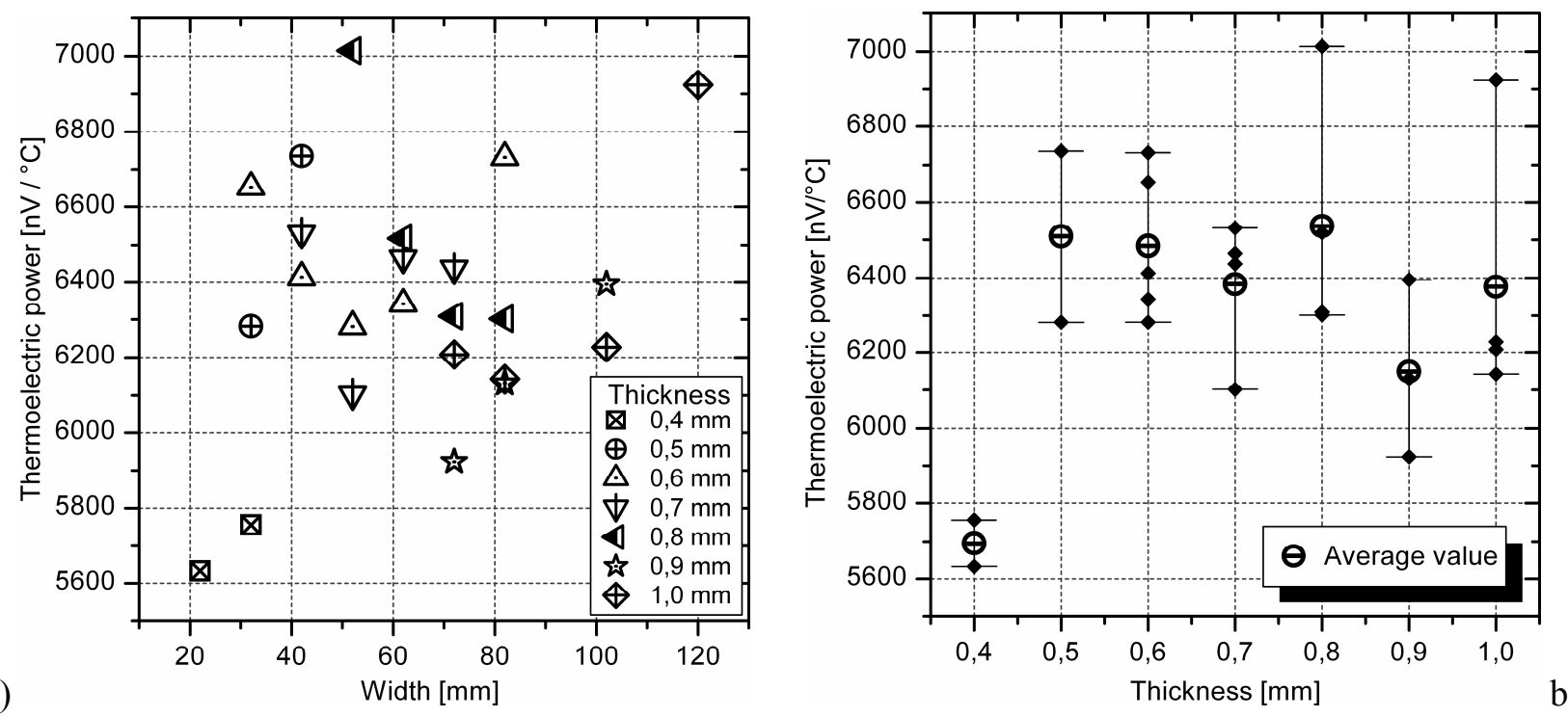

Figure 2. Thermoelectric power of C75S steel strips in function of strip width (a), in function of strip thickness (b).

\section{X-ray diffraction measurements}

The X-ray diffraction (XRD) analyses were performed to check the differences in the phase constitutions of the samples of the same material, with different TEP values. The main issue was the amount of the retained austenite. The measurements were performed on samples at which the TEP value was the minimum (sample "151"), maximum (sample "191") and mean (sample "173") of the interval shown in Fig. 2. On the mechanically grinded and polished samples the first series of XRD measurements were done by a Bruker Advance D8 diffractometer using CoK-alpha radiation. The step width was $0.1^{\circ}$ and the collecting time was $20 \mathrm{~s}$. Austenite wasn't detectable on the diffractograms so the samples were indistinguishable. Austenite peaks are not presented neither in case of finer step width and longer counting time.

So that new XRD analyses were also done on the two other steel strips, of which mechanical properties differed the most according to the observations of the producer of the bandsaw blades. The Seebeck-coefficient of sample „M" - with the best fatigue resistance - is $6490 \mathrm{nV} /{ }^{\circ} \mathrm{C}$ while this value is $5245 \mathrm{nV} /{ }^{\circ} \mathrm{C}$ at sample ,S", which is the most sensible to fatigue (this sample has different producer than the 270 samples of the TEP measurements). At the evaluation not just the usual austenite peaks [16] - corresponding to the austenite phase for the lattice parameter of $3.600 \AA$ - were considered, but an other peak for the lattice parameter of $3.4300 \AA$ [17] too, nevertheless this second lattice parameter is smaller than FCC lattice reliable on pure iron. The $\{111\}$ reflections of this small lattice parameter austenite can show up on the right of the ferrite $\{110\}$ peak. Fig. 3 shows, that there isn't definite austenite peak on neither side of the ferrite peak. The larger peak enlargement of sample „M" refers to finer microstructure at the same time.

The second serial of the XRD measurements was definitely concentrated on the steel strips „M” and ,S" to clarify whether there is any microstructural difference between the two materials, which is revealable by XRD. The measurements were repeated with $\mathrm{Cu}$ anode on the mechanically grinded and polished samples and the as fabricated surface too. 
It is clearly shown in Fig. $4 a$ that the peak of retained austenite definitely appears on the external surface of the steel strip with a notable amount, $20 \%$ or so. But after grinding the thin strip, the austenite is not or hardly measurable.

This means that it is not present or it's distribution and size has changed consequently can't be detected by XRD. Fig. $4 b$ shows the measurements taken from the as received external surface. It confirms that measurement with $\mathrm{Cu}$ anode shows the microstructural differences of "M" and ,S" steel strips according to the dispersion of ferrite-carbide structure and retained austenite content. The smaller enlargement of the ferrite-peak can cause this so that even the overlapping with the close austenite peak doesn't hide the fine portions.

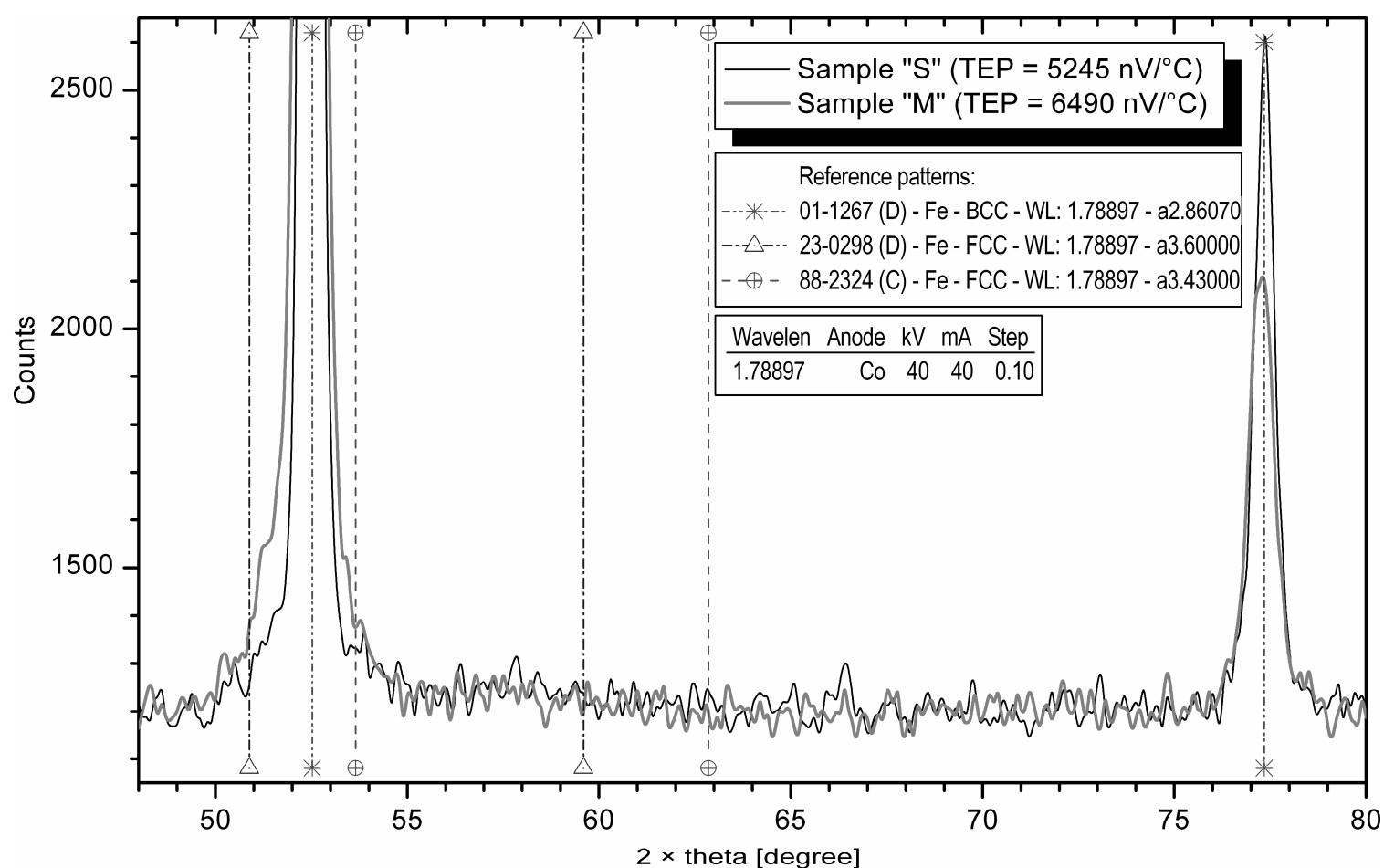

Figure 3. A part of X-ray diffractogram for two C75S steel strips. The fatigue resistance is high for the sample " $\mathrm{M}$ " and low for the sample "S". Anode material: cobalt.
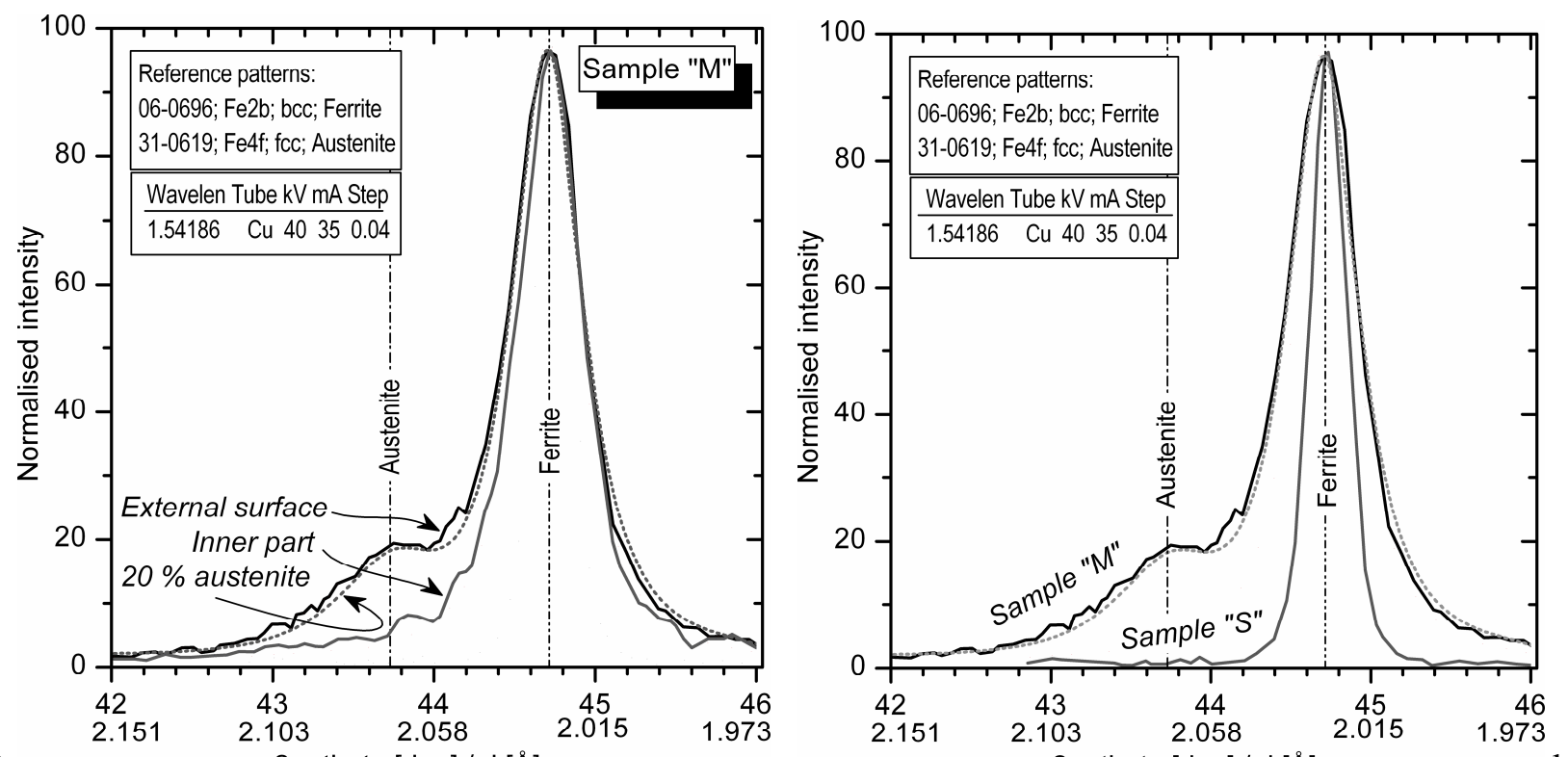

a)

$2 \times$ theta $[\mathrm{deg}] / \mathrm{d}[\AA]$

$2 \times$ theta $[\mathrm{deg}] / \mathrm{d}[\AA]$

Figure 4. Ferrite and austenite peak of sample " $M$ " from "as received" and grinded inner surface (a) and "as received" surface (b) of two different C75S steel strips (anode material: copper). 


\section{Electron backscattered diffraction analysis}

After the XRD analyses electron backscattered diffraction (EBSD) analyses were done. The aim of EBSD analyses was to control the quantitative results of XRD measurements, as well to show the structure of cementite indefinable with XRD measurements. The EBSD phase maps make possible to show the position of the retained austenite particles between the main constituent phases of the microstructure.

Fig. 5 shows the $20 \times 20$ micrometer phase maps of the samples, which have the smallest (sample "151") and the biggest (sample "191") TEP from the investigated 270 steel strips. It can be clearly seen that the average size of cementite particles is much smaller, the distribution of this particles is finer at sample "191" than at sample " 151 ". This difference can be seen better at "M" and " $\mathrm{S}$ " samples also shown in XRD analysis, of which phase maps shows the Fig. 6.

a)

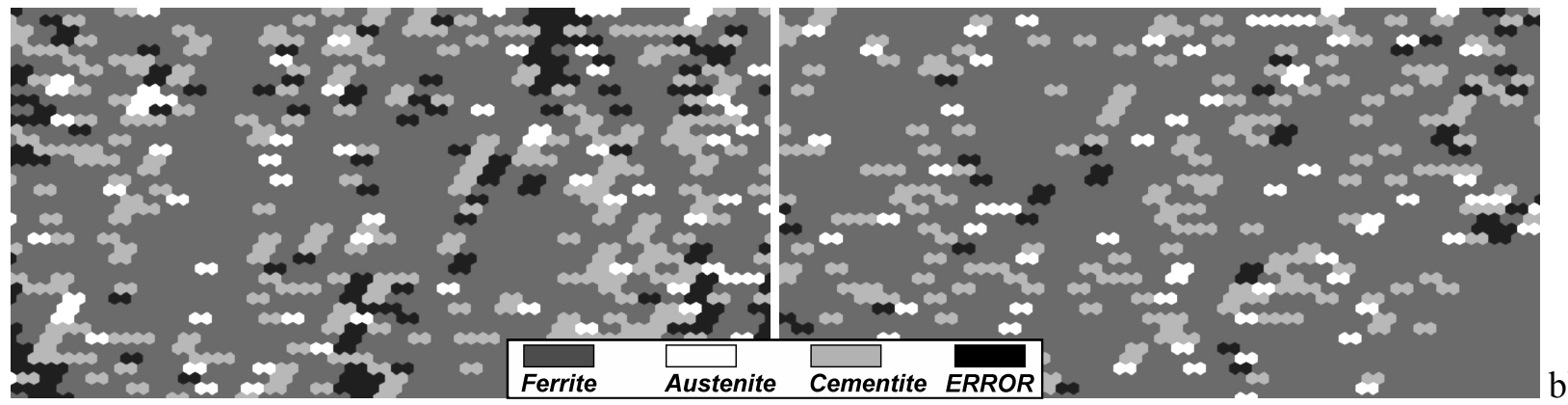

Figure 5. EBSD phase map (step=0.30 microns) of the sample "151" (a) and the sample "191" (b).

a)

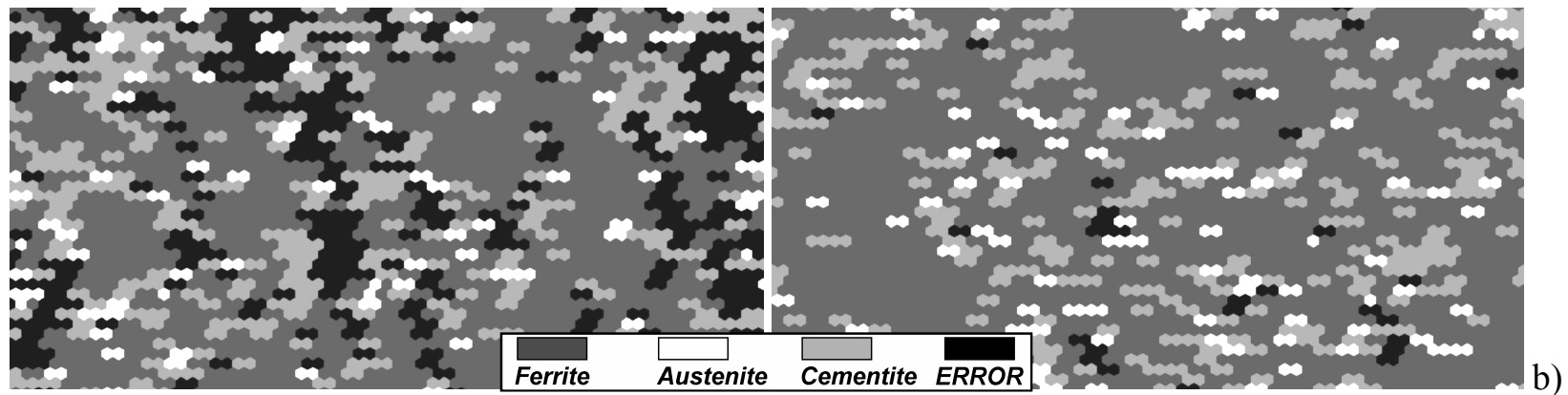

Figure 6. EBSD phase map (step=0.30 microns) of the sample " $M$ " (a) and the sample "S" (b).

The retained austenite content could be shown in all four examined samples, also in "S" sample, at which it couldn't be shown with XRD measurement. Furthermore, the EBSD measurement showed exactly in this sample the most retained austenite $(8,6 \%)$ and the less $(4,3 \%)$ in the sample "191" with the highest dispersion of cementite.

According to the phase maps, the size of retained austenite particles is closely connected to the size of cementite particles, especially when it has a common phase boundary with cementite. The particles of retained austenite are also present in ferrite (in the original martensite phase), but there they are always much finer than those, which are on the ferrite-cementite boundary. The coincidence of austenite-ferrite phase boundaries is presented in the work of Gaál and Szabó [18].

\section{Conclusions}

Examining the great amount of tempered eutectoid steel strips it was proved that important differences can be measured by thermoelectric power measurement between steel strips with nearly the same mechanical properties and chemical composition. The TEP measurement sensitively shows the different conditions of the microstructural properties.

The measured differences concern to the volume not the surface properties of the material, because thermoelectric phenomenon is based on physical processes happening in the whole volume of the material. 
The average thermoelectric power of eutectoid steel strips is $6300 \mathrm{nV} /{ }^{\circ} \mathrm{C}$. This value mostly depends on the thickness of the plate and slightly reduces while it is rising. This general trend doesn't valid for the investigated thinner $(0,4 \mathrm{~mm})$ strip.

Among the microstructural properties the role of two important factors turned out: firstly - and more important - the dispersion of the distribution of cementite in ferrite-cementite mixture, secondly the amount and distribution of retained austenite.

According to the high-cycle fatigue properties, it is likely that the rise of fatigue resistance is caused by the rise of the dispersion of cementite, which means the reduction of the amount of the retained austenite simultaneously.

By the XRD analysis it was proved that the small retained austenite content of the samples containing big amount and disperse distributed cementite can be detected more successfully using $\mathrm{Cu}$ anode, but the detection limit is only about $4-5 \%$.

The EBSD analysis clarified that the size of retained austenite phase rises with the size of cementite particles in case of having common phase boundary with cementite. In other cases, when retained austenite has a common boundary only with ferrite, its size remains between $300-400 \mathrm{~nm}$ always.

\section{Acknowledgements}

This work connects to the Hungarian R\&D project "TUDAS-1-2006-0049". The author acknowledges financial support from Hungarian Research Fund (OTKA T69122) and Bolyai Janos Research Fellow of the Hungarian Academy of Sciences. Moreover, the author would like to thank István Sajó (MTA KKK), Jenő Sólyom (University of Miskolc) and Zoltán Gaál for support in XRD and EBSD analyses.

\section{References}

[1] H.P. Klug, L.E. Alexander: X-Ray Diffraction Procedures for Polycrystalline and Amorphous Materials. John Wiley \& Sons, 1974.

[2] I. Tkalcec, C. Azcoïtia, S. Crevoiserat, D. Mari: Mater. Sci. Eng., A. Vol. 387-389 (2004), p. 352.

[3] X. Sauvage, J.M. Le Breton, A. Guillet, A. Meyer, J. Teillet: Mater. Sci. Eng. A. Vol. 362 (2003), p. 181.

[4] N. Lavaire, V. Massardier, J. Merlin: Scripta Mater.Vol. 50 (2004), p. 131.

[5] V. Massardier, V. Guetaz, J. Merlin, M Soler: Mater. Sci. Eng., A. Vol. 355 (2003), p. 299.

[6] J. Merlin, S. Garnier, M. Bouzekri, M. Soler: Rev. Metall. / Cah. Inf. Tech. Vol. 101 (2004), p. 403.

[7] D. Benkirat, P. Merle, R. Borrelly: Acta Metall. Vol. 36 (1988), p. 613.

[8] Ch. Sidoroff, P. Franciosi, A. Vincent, D. Girodin, G. Dudragne: Mécan. Indus. Vol. 3 (2002), p. 503.

[9] I. Meszaros, J. Prohaszka: J. Mater. Process. Technol. Vol. 161 (2005), p. 162.

[10] E. Nagy, V. Mertinger, F. Tranta, J. Solyom: Mat. Sci. Forum. Vol. 414-415 (2003), p. 281.

[11] X. Kleber, F. Fouquet, M. Delnondedieu: Scripta Mater. Vol. 51 (2004), p. 1171.

[12] I. Meszaros, J. Ginsztler: Mater. Sci. Forum. Vol. 537-538 (2007), p. 419.

[13] J. Dobranszky, P.J. Szabo, T. Berecz, V. Hrotko, M. Portko: Spectrochim. Acta, Part B. Vol. 59 (2004), p. 1781.

[14] Y.-D. Park: Metals and Materials Int. Vol. 10 (2004), p. 237-244.

[15] M. Takács, B. Verő: Mater. Sci. Forum Vol. 473-474 (2005), p. 273-278

[16] V.M. Goldschmidt: Metallurgia. Vol. 40 (1940), p. 103.

[17] J. Haglund, F. Fernandez-Gullermet, G. Grimvall, M. Korling: Phys. Rev. B: Condens. Matter. Vol. 48 (1993), p. 11685.

[18] Z. Gaál, P. J. Szabó: Evolution of Grain Boundaries in Austenitic Stainless Steels, Mater. Sci. Forum, Vol. 537-538 (2007), p. 355. 